\title{
ANALYZING THE RENT-TO-PRICE RATIO FOR THE HOUSING MARKET AT THE MICRO-SPATIAL SCALE
}

\author{
Changro LEE ${ }^{1, *}$, Keyho PARK ${ }^{2}$ \\ ${ }^{1}$ Institute for Korean Regional Studies, Seoul, South Korea \\ ${ }^{2}$ Department of Geography, Seoul National University; Institute for Korean Regional Studies, Seoul, South Korea
}

Received 07 December 2017; accepted 28 February 2018

\begin{abstract}
The rent-to-price ratio is one of the popular indicators for monitoring the property market. This study explores micro-scale spatial dynamics of the ratio for houses at the individual property level in Seoul, South Korea. We match the apartment unit sold and the one leased based on the carefully chosen criteria and apply a Bayesian multi-level modeling approach to this matched dataset. We employ the Integrated Nested Laplace Approximations (INLA) algorithm in order to estimate relevant parameters in the multi-level model. The ratio determinants found in the study include property age, apartment unit area, interest rate, and floor. This study also presents the importance of taking into account the hierarchical structure of apartment units, as well as seasonal and spatial variations when estimating the ratio and predicting future trends in the property market based on the ratio.
\end{abstract}

Keywords: rent-to-price ratio, Bayesian multi-level model, hierarchical structure, seasonal variation, spatial variation, apartment unit.

\section{Introduction}

The relationship between house prices and rents has always been a major concern for parties in the housing market. The rent-to-price (or price-to-rent) ratio has been a popular indicator for monitoring the housing market, and considerable literature on the housing market has assumed that there exists a fundamental relationship between house prices and rents. For example, André, Gil-Alana, and Gupta (2014) empirically analyzed price-to-income and priceto-rent ratios in a sample of 16 OECD countries spanning four decades, and found that the ratios are highly consistent, almost always showing the tendency to return to their historical average value. In accordance with this finding, ratios that have deviated from their long-term values have often raised concerns among various parties in the housing market, such as houses being overvalued. In South Korea, housing takes up a considerable portion (more than 70\%) of household assets (Ronald \& Jin, 2015), and rent also represents a major expenditure (Households with rent-to-income ratios exceeding $30 \%$ was $34.7 \%$ in 2006) for tenants (Kang et al., 2006). The ratio has also played a particularly important role in the managing of property portfolios by investors, as different ratios across regions require different strategies for portfolio management.
Scholars and policy makers have paid special attention to the low rent-to-price ratio ${ }^{1}$, since it usually signifies an overvaluation, or bubble, in housing prices, and thus implies that the affordability of decent housing decreases in proportion to a decline in the ratio. Therefore, governments in many countries employ various economic controlling policies, such as strengthening mortgage regulations, to cool off housing booms during periods with a low rent-to-price ratio.

In contrast, the government of $\mathrm{S}$. Korea has monitored the rising rent-to-price ratio closely, since it indicates a decrease in affordability of houses for tenants. Unfortunately, the housing market in S. Korea has experienced a drastic increase in the rent-to-price ratio since the 2008 global financial crisis as shown in Figure 1, causing severe social problems, such as more difficulty in finding decent housing under the lease agreement.

\footnotetext{
1 The terms rent-to-price ratio or price-to-rent ratio are chosen depending on the researchers' preference and convenience, and are used interchangeably in literature. This study chooses to refer to the ratio as the rent-to-price ratio, since it is the term used most frequently in both academic papers and policy reports in S. Korea.
}

${ }^{*}$ Corresponding author. E-mail: spatialstat@naver.com 


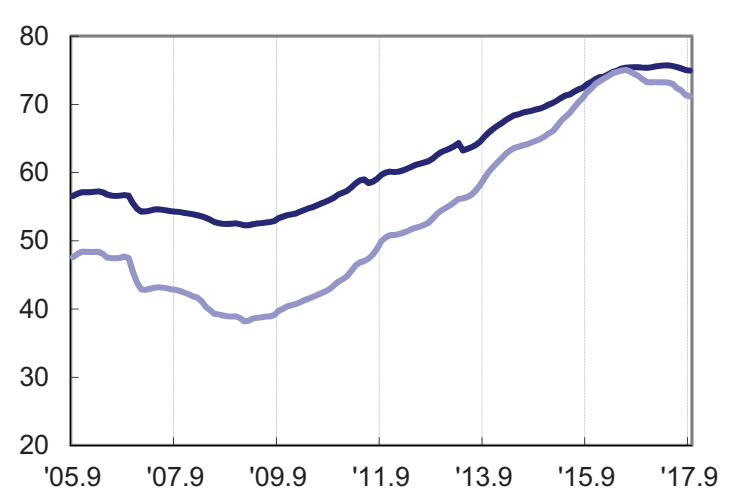

Figure 1. Changes in the rent-to-price ratio between September 2005 and September 2017

Darker line denotes the nationwide trend and light one indicates the trend in Seoul (unit: \%) (source: KB Kookmin Bank, Ratio of rent (Jeonsei) to purchase price for apartment)

In this paper, through a Bayesian multilevel modeling approach, we study the determination of the rent-to-price ratio for houses in the Seoul Metropolitan Area (hereafter, Seoul), S. Korea. We examine the determinants of the ratio at the individual property level, and investigate temporal and spatial variations of the ratio as well. This will provide insights into the dynamics of the S. Korean housing market system, the housing policy for local governments, and the strategy for property companies.

Past studies of the ratio have largely examined the time-series relationship between house prices and rents at the national or regional scale, using aggregated data. Research has thus not convincingly explained how the ratio is distributed spatially at the individual property level, how it varies across property characteristics, or what the implications of this are for particular local governments or property companies. This paper attempts to address these issues through an empirical analysis of recent data collected by the authors.

Our examination of the relationship between house prices and rents not only contributes to understanding the micro-scale dynamics of the ratio from a spatial perspective while avoiding the biases introduced by aggregation of data, but also reveals features in the ratio of S. Korean housing market, such as its determinants and variations.

This study proceeds from a review of lease practices in S. Korea; the second section then addresses the ratiorelated literature, and the third section explains the data used and model specification. Model calibration and main results are provided in the fourth section, and finally, a discussion on the results and conclusions are presented.

\section{Lease practices in S. Korea}

In the term "rent-to-price ratio", rent denotes the deposit paid to the landlord under a Jeonsei agreement. The lease practices in S. Korea are rather peculiar compared to those in other countries. Monthly rent contracts and Jeonsei agreements are the most popular lease types in S. Korea.
They respectively make up $47 \%$ and $36 \%$ of the total lease contracts (Korean Statistical Information Service, 2016). The monthly rent contract follows the usual month-based payment system, with the deposit equal to two or three years' worth of monthly rent. The tenant usually pays a lower monthly rent if the deposit is large. In contrast, the Jeonsei is a lease agreement in which the tenant pays a considerable deposit, usually about half or more of the house's market value to the landlord. The tenant can live in the house rentfree during the lease period, and the deposit, or the Jeonsei deposit, is refundable without any interest at the end of the lease term. The Jeonsei agreement is a good option for many people, since they can escape the burden of paying rent. The rent-to-price ratio in the study is calculated by dividing the Jeonsei deposit by the market value of the house.

Although the Jeonsei agreement seems to be unusual from a European perspective, this lease practice has long thrived in S. Korea. The Jeonsei agreement provided landlords with interest income of the Jeonsei deposit, and a capital gain of the house during periods of high interest rates, and rapid appreciation of house price. From the tenants' perspectives, they have the right to reside in the house paying no rent during the lease period, typically two years. In S. Korea, most tenants have the idea that monthly rents are "wasted money", whereas the Jeonsei deposit represents a sort of "forced saving" or even an investment (Kim, Choi, \& Ko, 2009).

The Jeonsei agreement and the monthly rent system are closely connected to each other in the housing market. This connection is best represented by the deposit-to-rent conversion rate (Park, 2002; Lee, Chung, \& Choi, 2009), a rate used to convert the amount of the Jeonsei deposit to rental payments. The KB Kookmin Bank (2017) reports that the average conversion rate is $4.33 \%$ in Seoul on September 2017 , while the annual interest rate for bank deposit is $1.70 \%$ for the same month and year. When 50 million KRW of the Jeonsei agreement is offered from a landlord, a prospective tenant might negotiate the agreement with a modified term, for example, 20 million KRW of the deposit and about $108,000 \mathrm{KRW}$ of the monthly rent (the remaining 30 million KRW multiplied by $4.33 \%$, and divided by 12 months) with the landlord. In general, young households start to reside in cheap housing with the monthly rent contract since they do not have lump-sum money available for the Jeonsei agreement. Then they move to better housing through the Jeonsei agreement, and finally come to occupy houses as homeowners. This is a typical housing ladder in S. Korea, though this pattern has weakened gradually in recent years.

The Jeonsei is now being rapidly replaced by the monthly rent system. More and more landlords are choosing to let their houses for monthly rent rather than through the Jeonsei agreement, amid a historically low deposit interest rate and uncertain outlook for increases in housing prices. The rapid shift from the Jeonsei to the monthly rent has caused a shortage in supply for houses available for the Jeonsei, and thus a sharp increase in the Jeonsei deposit, ultimately leading to the rising rent-toprice ratio as shown in Figure 1. 
The remarkable increase in the ratio in the housing market since the 2008 crisis gave rise to a number of academic studies and media news reports, as well as a variety of policy responses. This study was initiated from this enhanced sociopolitical attention to the ratio.

\section{Literature review}

Shiller (2015) reviews housing data of the United States housing market over the 1890-2005 period, and finds a noticeable decline in the rent-to-price ratio between 1995 and 2005. He suggests that the increase in house prices compared to rents over the same period is unparalleled since 1960. He concludes that there exists a considerable bubble in US housing prices over the 1995-2005 period. His study ignited strong attention to the relationship between house prices and rents, and similar studies were conducted in the same context of diagnosing price bubbles based on changes in the rent-to-price ratio (Ayuso \& Restoy, 2006; Davis, Lehnert, \& Martin, 2008; Hatzvi \& Otto, 2008).

Assuming that there exists an intrinsic relation between sale prices and rents, numerous studies have been attempted. Chen (1996) investigates the fledgling house market of China and points out that rents on public housing are remarkably lower due to the low-rent policy enforcement, which leads to the irrationally high price-to-rent ratio. This study argues that the distorted price-to-rent ratio in the Chinese housing market should be lowered by raising rents to the level of other costs, one example being the labor wage level. Gallin (2008) investigates how well the rent-to-price ratio predicts future trends in property markets, and suggests that the ratio is a useful reference of appraisal in the US housing market. Kim and Lim (2014) use an unobserved component model to decompose the price-to-rent ratio in the Irish housing market, and find that the variations in the price-to-rent ratio are mostly due to the expected housing premium. Kishor and Morley (2015) investigate which factors determined the price-to-rent ratio for the U.S. housing market on a national level over the period of 1975-2014, and find that the ratio is sensitive to the mortgage interest rate. Campbell, Davis, Gallin, and Martin (2009) employ a vector autoregression (VAR) approach to explain the movements in the price-to-rent ratio in US metropolitan areas, and find that the housing risk premium accounts for an important fraction of the ratio.

Another key aspect of house pricing studies is that of methodological advance. Since house prices and rents are collected across regions over time, they usually take the form of panel data, and thus various econometric techniques for space-time analysis naturally developed in this field. House prices and rents are characterized by cross-sectional as well as temporal dependence, and thus it deserves to mention the common correlated effects (CCE) estimator which was developed recently to eliminate both forms of dependence in heterogeneous dynamic panels. This estimator was proposed by Pesaran (2006) and was utilized for showing the relationship between house prices and economic fundamentals in Holly, Pesaran, and Yamagata (2010) and Baltagi and $\mathrm{Li}$ (2014). In both of the studies, per capita income rather than rents is used as a proxy variable for economic fundamentals. Holly et al. (2010) analyze house prices and per capita income through an error correction model using the CCE estimator, and conclude that there is little evidence of housing price bubbles at the national level in the USA during the period between 1975 and 2003. Baltagi and Li (2014) extends the study of Holly et al. (2010) using a longer time period and a higher level of disaggregation (from 49 US states to 381 Metropolitan Statistical Areas) and find that the results of Holly et al. (2010) are robust to the time period and the finer geographic units.

Laurini (2017) points out that although the CCE estimator is robust to the presence of spatial effects, it is not possible to directly interpret the spatial effects. He uses the same data as used by Baltagi and $\mathrm{Li}$ (2014), but employs an error correction model with the inclusion of continuous spatial random effects, using a space-time model based on a spatial covariance matrix of the Matérn class. His estimation method depends on a Bayesian inference based on integrated nested Laplace approximations, which is similar to that used in this study. His results confirm the existence of a co-integration relationship between house prices and per capita income.

Although the rent-to-price ratios have been analyzed repeatedly in a number of studies, most of them have used aggregated data at the national or regional level due to the lack of available data. It could be understood without difficulty that rents and prices of housing are not easily available at the property level. However, spatial aggregation of data in calculating the ratio can give rise to a bias in the estimated value. This bias could stem from two sources: the first is that the size, construction workmanship, and location of houses sold are greatly different from those rented (Hattapoglu \& Hoxha, 2014) - which is colloquially referred to as "comparing apples and oranges". The modifiable areal unit problem (MAUP) could be pointed out as a second source for causing the bias. The MAUP is a well-known problem in geography and spatial analysis. The MAUP rose from the imposition of artificial units of reporting on continuous geographic phenomena, resulting in the generation of artifacts or errors (Ian, 2010). Ratio data is usually aggregated by administrative areas. However, the administrative boundaries are arbitrarily determined by a government agency, and thus have little relationship with housing market areas, of which boundaries are unofficially determined by purchasers, sellers, brokers, and investors. Thus, use of spatially aggregated data is a highly possible origin of the MAUP.

In addition, most previous analyses have been conducted more often than not within the time series analytical framework in econometrics and finance. Therefore, previous studies naturally tend to focus on the analysis of temporal variation in the ratio on a national scale and its economic implications, such as variance decomposition of the ratio series and the long-term equilibrium ratio.

While this approach employed in previous studies can provide a tool for judging bubble identification in housing price and property investment potential, it cannot provide information about a particular property. That is, little is known from previous studies about the behavior of the ra- 
tio from the micro-scale spatial perspective, and its features at the individual house unit level. This study attempts to explore cross-sectional differences in the ratio explicitly, and find important features of the ratio at the property level.

\section{Data and model specification}

\subsection{Seoul Metropolitan Area}

This study analyzes the rent-to-price ratio for apartments in Seoul, S. Korea. Seoul is the capital of S. Korea with a population of over 10 million, distributed over $605.2 \mathrm{~km}^{2}$ of administrative areas. The population density is 16,492 persons per $\mathrm{km}^{2}$ (Seoul, 2016), one of the highest levels among the top global cities. The total housing stock in Seoul is made of 2,830,857 units as of 2016 and apartment units make up about 58 percent of that, as shown in Table 1 . Thus, apartments can be said to be a representative housing type in Seoul. Figure 2 shows the administrative map of Seoul with 25 districts.

Table 1. Housing stocks in Seoul (2016) (source: Korean Statistical Information Service (www.kosis.kr))

\begin{tabular}{|c|c|c|c|c|}
\hline $\begin{array}{c}\text { Single-family } \\
\text { house }\end{array}$ & Apartments & $\begin{array}{c}\text { Row } \\
\text { house }\end{array}$ & Others & $\begin{array}{c}\text { Total } \\
\text { (units) }\end{array}$ \\
\hline 345,269 & $1,641,383$ & 815,552 & 28,653 & $2,830,857$ \\
\hline $12 \%$ & $58 \%$ & $29 \%$ & $1 \%$ & $100 \%$ \\
\hline
\end{tabular}

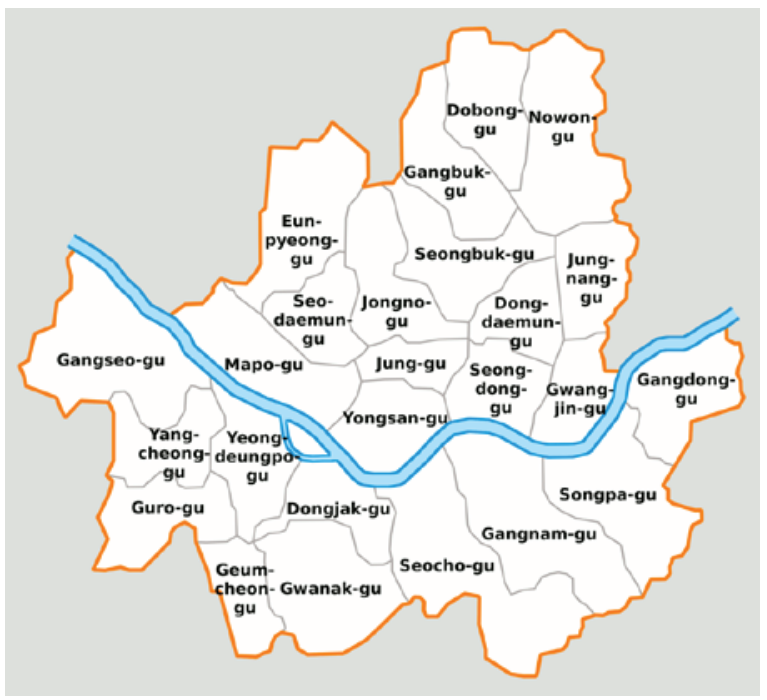

Figure 2. Administrative map of Seoul with 25 districts (source: Commons, 2012 (https://commons.wikimedia.org/wiki/Talk:Seoul))

\subsection{Data}

The data were collected at the individual apartment unit level in monthly periods between January of 2016 and December of 2016 from the Real estate Transaction Management System (RTMS). The Minister of Land Infrastructure and Transport operates the RTMS related to such affairs as contracting, reporting, etc. of real estate transactions for efficient management of property information and appropriate establishment of real estate policies, as prescribed by the Act on Report on Real Estate Transactions. Therefore, transaction parties should report matters prescribed by the Act, including the transaction price, to the relevant government agency. The RTMS discloses the sale prices and rents on a monthly basis. As for the rents, the RTMS provides rent data under both Jeonsei agreements and monthly payment contracts. We collect only the rents under Jeonsei agreements and exclude the monthly payment contracts. In order to calculate the rent-to-price ratio of each apartment unit, we matched the unit sold and the one leased based on the following four criteria: the apartment complex to which the unit belongs, the unit area, the floor on which the unit is located, and the month in which the sale or lease contract was made. In other words, we consider the sold unit and the leased unit to be identical when they are located in the same apartment complex, are located on the same floor, have the same unit areas, and were contracted on the same month.

We finally rest in the apartment unit samples presented in Table 2. There are a total of 11,075 units in 919 apartment complexes in the study region, with per square meter sale prices ranging between 2,591,000 and 26,231,000 KRW. Jeonsei deposit per square meter ranges from 940,000 to 15,677,000 KRW. As seen in Table 2, the typical rent-to-price ratio of apartments in Seoul ranges from $69 \%$ to $75 \%$, meaning that about $70 \%$ of the market value is paid to the landlord in order to escape the burden of paying monthly rent during the lease period. Sale prices, Jeonsei deposits, and their ratio distributions are presented graphically in Figure 3. The unit area varies from $25 \mathrm{~m}^{2}$ to $243 \mathrm{~m}^{2}$, as luxurious apartment units can be as large as $250 \mathrm{~m}^{2}$. The average age of apartment buildings transacted in 2016 is 20 years or more, and we observe that the transaction volume tends to be heavier between June and October during the year.

Table 2. Descriptive statistics (11,075 units in 919 complexes)

\begin{tabular}{|c|c|c|c|c|}
\hline & Min. & Mean & Median & Max. \\
\hline Unit area $\left(\mathrm{m}^{2}\right)$ & 25 & 71 & 66 & 243 \\
\hline Floor & 1 & 8.5 & 8 & 25 \\
\hline Age (year) & 0 & 21 & 22 & 45 \\
\hline Sale prices $\left(1,000 \mathrm{KRW} / \mathrm{m}^{2}\right)$ & 2,591 & 7,875 & 6,631 & 26,231 \\
\hline Jeonsei deposit $\left(1,000 \mathrm{KRW} / \mathrm{m}^{2}\right)$ & 940 & 4,959 & 4,713 & 15,677 \\
\hline Ratio (\%) & 4 & 69 & 75 & 99 \\
\hline \multirow[t]{3}{*}{ Monthly transaction volume } & Jan. 424 & Feb. 445 & Mar. 955 & Apr. 1047 \\
\hline & May 970 & Jun. 1172 & Jul. 1178 & Aug. 1175 \\
\hline & Sep. 1217 & Oct. 1474 & Nov. 538 & Dec. 480 \\
\hline
\end{tabular}



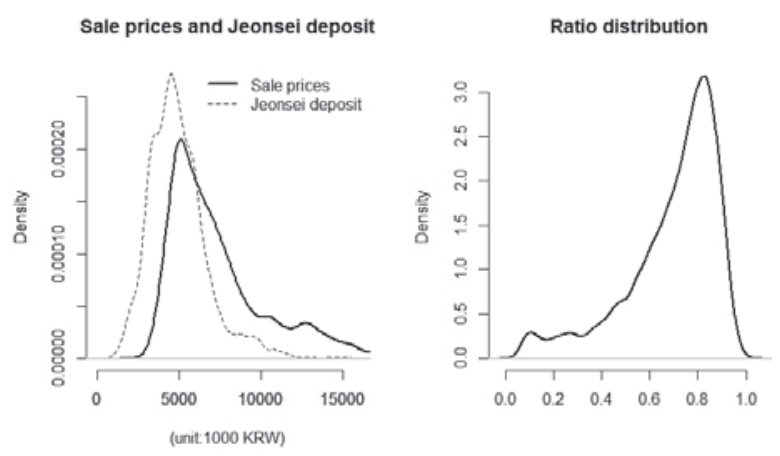

Figure 3. Sale prices, Jeonsei deposit and their ratio distribution

\subsection{Data characteristics}

Apartment units have a natural hierarchy in that individual units are nested within an apartment complex. The data for this study could be categorized into two levels: individual units (level 1) and apartment complexes (level 2). It is expected that the sale prices or rents of units within the same apartment complex are more similar to one other than to units of other apartment complexes, as they share common features such as location, building quality, complex layout, etc. We need to take into account the hierarchical structure of apartment units explicitly, and the interdependence among sale prices or rents within the same apartment complex. In this sense, a multilevel modeling approach has the needed flexibility and efficiency for modeling these data characteristics (Goldstein, Pan, \& Bynner, 2004; Shor, Bafumi, Keele, \& Park, 2007).

When the data are collected over time and space, it is usual that the data value in one period correlates with the value in previous period, and the value in one space correlates with the values in neighboring spaces. The former and latter are called serial and spatial correlations, respectively. The sale prices and rents in this study are collected over 12 sequential months, and thus they are typical series data. The data are collected over the area of Seoul, and thus they naturally show spatial dependence among their values. In property valuation, it is well known that the closer houses are located to each other, the more similar their prices or rents. Figure 4 and 5 show serial and spatial correlations inherent in the data. It is clear that the ratio in the current month is similar to the one in the previous month, and thus, Figure 4 suggests that the serial correlation should be explicitly accounted for when specifying a model. Figure 5 also implies that the ratio is not distributed independently over space, but rather tends to show similar values in neighboring areas, indicating that the spatial correlation should be incorporated into model specification. The southeastern region of Seoul is where the ratio is lower than 0.7. On the other hand, the ratio in the northeastern region of Seoul is relatively high, ranging from 0.8 to 0.9 . The ratio in the rest area appears to be between 0.7 and 0.8. In summary, Figure 4 and 5 indicate that both the serial and spatial interdependences are important components which deserve careful handling when building a quantitative model.

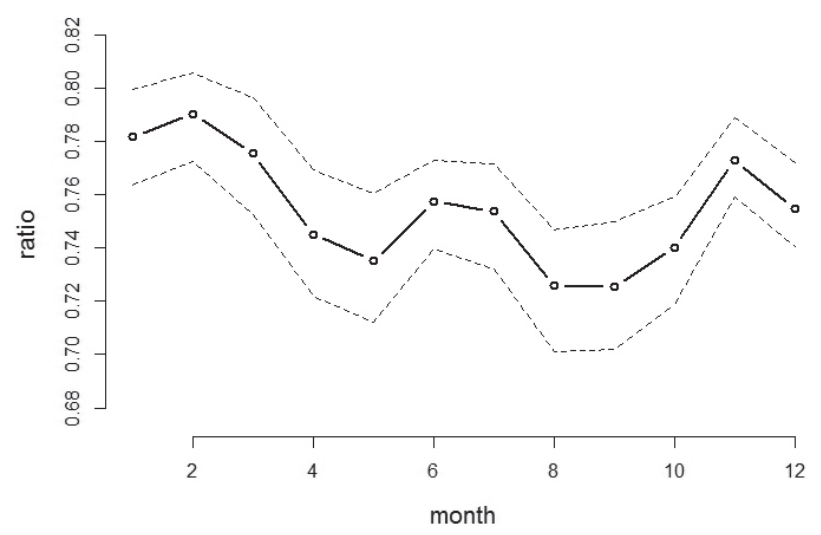

Figure 4. Serial correlation of the rent-to-price ratio

Solid line indicates a median ratio of each month and dotted lines show 40th and 60th percentile ratios of the corresponding month.

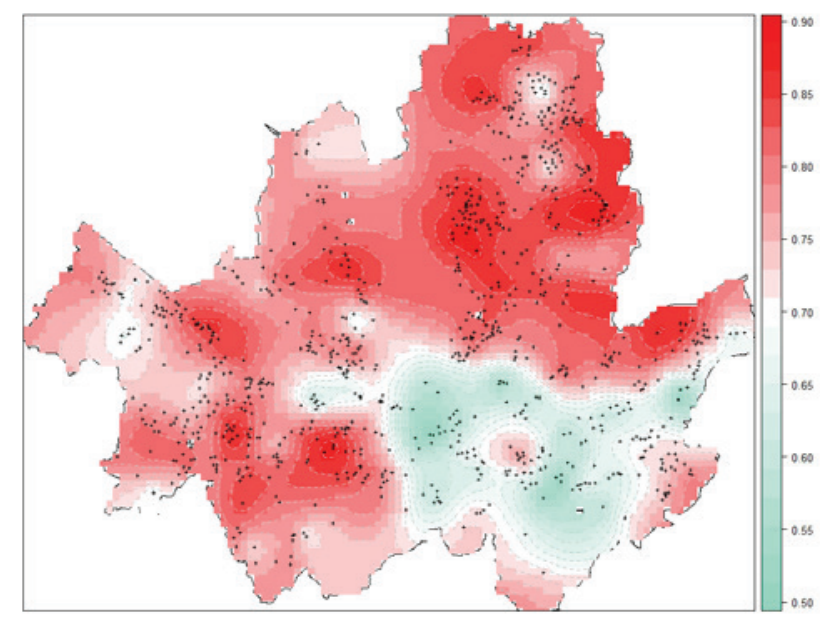

Figure 5. Spatial correlation of the rent-to-price ratio

The symbol "+" indicates the location of the apartment complex, and the ratio is the average value between January and December of 2016. The ratio surface is created by a kriging method, a common technique for spatial interpolation.

\subsection{Explanatory variables}

Factors affecting the ratio could be enumerated endlessly. From the perspective of housing demand, some important variables include purchaser's income, mortgage interest rate, and credit regulations. Land zoning and construction costs could have a strong influence when it comes to housing supply. Therefore, selecting explanatory variables must be a compromise between theory and data availability.

We employ the area of each unit, the floor on which the unit is located, the age of the apartment complex, and the 3-year corporate bond interest rate as explanatory variables in model building. In addition to these explicit variables, we also consider the hierarchical structure of units nested in the complex, seasonal effect of ratio values, and geographic locations of each complex as the components 
of model specification. Therefore, we believe that we include all the basic and fundamental variables affecting ratio values in the model specification under the constraints of data collectability.

\subsection{Model formula}

We assume the following normal distribution for $y_{i j t}$ in referring to the rent-to-price ratio of apartment unit $i(i=$ $1, \ldots, 11,075)$ in complex $j(j=1, \ldots, 919)$ on month $t(t=$ $1, \ldots, 12)$ :

$$
y_{i j t} \sim \operatorname{Normal}\left(\mu_{i j t}, \sigma^{2}\right) \text {. }
$$

The expected mean $\mu_{i j t}$ is explained by the following explanatory variables:

$$
\mu_{i j t}=\beta_{0 j}+\boldsymbol{x}_{\boldsymbol{i}} \boldsymbol{\beta}_{\text {unit }}+\boldsymbol{x}_{\boldsymbol{j}} \boldsymbol{\beta}_{\text {complex }}+x_{t} \beta_{\text {time }}+\gamma_{t}+u_{j} .
$$

It includes linear effects $\boldsymbol{\beta}$ for the apartment unitlevel explanatory variables $\boldsymbol{x}_{\boldsymbol{i}}$ (unit area and floor), for the apartment complex-level explanatory variables $\boldsymbol{x}_{\boldsymbol{j}}$ (age and its square), and for the month-basis variable $x_{t}$ (monthly reported 3-year bond interest rate).

It also includes an intercept $\beta_{o j}$. We specify a hierarchical structure, which assumes an intercept for each apartment complex as in the following:

$$
\beta_{o j}=\beta_{0}+v_{o j}, v_{o j} \sim \operatorname{Normal}\left(0, \sigma_{v_{0}}^{2}\right) \text {. }
$$

It considers an intercept for each apartment complex through the hierarchical or multilevel specification. Our model also includes separate components for the temporal and spatial effects. $\gamma_{t}$ represents the temporal correlation, and is modelled using a random walk of order 1 as in the following:

$$
\gamma_{t} \sim \operatorname{Normal}\left(\gamma_{t-1}, \sigma_{\gamma}^{2}\right)
$$

where: $t$ represents the month in 2016 that sale prices and rents are measured, that is, $t=1, \ldots, 12$.

Finally, $u_{j}$ represents the spatial correlation. Geostatistical data are realizations of a spatial process, and the spatial process is a Gaussian field (GF) if the response vector follows a multivariate normal distribution with mean $\mu$ and spatial covariance matrix $\Sigma$. The main problem of the modeling approach involving the covariance matrix is the computational burden related to calculations with dense covariance matrices (Banerjee, Carlin, \& Gelfand, 2014). A computationally effective alternative is the stochastic partial differential equation (SPDE) approach (Lindgren, Rue, \& Lindström, 2011) and consists of performing the calculations using a Gaussian Markov random field (GMRF, a discretely indexed spatial random process) representation of GF. GMRF is characterized by sparse precision matrices (the inverse covariance matrices), and therefore fast computational time. The SPDE approach can be formulated as following.

$$
\left(\kappa^{2}-\Delta\right)^{\alpha / 2}(\tau \xi(s))=W(s),
$$

where: $s$ is a spatial index; $\Delta$ is the Laplacian; $\alpha$ controls the smoothness; $\kappa$ is the scale parameter; $\tau$ controls the variance; $\xi(s)$ denotes GF, and $W(s)$ is a Gaussian spatial white noise process (see Lindgren et al. (2011) for additional details and interpretation of parameters). The solution to this SPDE is the GF $\xi(s)$ with covariance function given by

$\operatorname{Cov}\left(u_{A}, u_{B}\right)=\frac{\sigma^{2}}{\Gamma(\lambda) 2^{\lambda-1}}\left(\kappa\left\|s_{A}-s_{B}\right\|\right)^{\lambda} K_{\lambda}\left(\kappa\left\|s_{A}-s_{B}\right\|\right)$.(5)

In other words, $u_{j}$ is supposed to be distributed as GF with the Matérn covariance function between two apartment complexes. $\left\|s_{A}-s_{B}\right\|$ is the Euclidean distance between complex A and complex B, and $\sigma^{2}$ is the marginal variance. $K_{\lambda}$ denotes the modified Bessel function of the order $\lambda$, which measures the degree of smoothness of the spatial process and is usually kept fixed due to poor model identifiability. $\kappa$ is the scale parameter related to the range $r$, i.e. the distance at which the spatial correlation becomes almost null (Blangiardo \& Cameletti, 2015, p. 194).

For point-referenced data like ones used in the study, the above solution to the SPDE (the stationary and isotropic Matérn GF $\xi(s)$ ) can be approximated using the finite element method through a basis function representation defined on a triangulation of the domain $D$.

$$
\xi(s)=\sum_{g=1}^{G} \varphi_{g}(s) \tilde{\xi}_{g},
$$

where: $\mathrm{G}$ is the total number of vertices of the triangulation; $\varphi_{g}$ is the set of basis functions, and $\tilde{\xi}_{g}$ are zero mean Gaussian distributed weights. That is, the result is a basis function representation with piecewise linear basis functions, and Gaussian weights with Markov dependence determined by a triangulation of the domain (Lindgren et al., 2011).

\subsection{Model selection}

We start from a simple model: that is, an ordinary singlelevel model with the four explanatory variables given in the Explanatory variables subsection (Model A). Then we specify a two-level hierarchical model (Model B), and refine Model B by explicitly taking into account a serial correlation via a random walk specification for a term representing the temporal pattern of the ratio (Model $\mathrm{C}$ ). And finally, we arrive at Model D, which is a two-level hierarchical model that accounts for both serial and spatial correlations. The response variable is the rent-to-price ratio, and all the candidate models are defined by the same four explanatory variables.

The models are fitted by the Bayesian estimation method (the specific algorithm will be explained in Section 4.), and we choose log-likelihood and the deviance information criteria (DIC) as model selection measures. Table 3 shows the values of log-likelihood and DIC for each model.

As it goes from the simple single-level model to the two-level model with both correlations taken into account, log-likelihood goes up, and DIC values continue to drop. It 
Table 3. Comparison of candidate models

\begin{tabular}{|l|c|c|}
\hline \multicolumn{1}{|c|}{ Model } & Log-likelihood & DIC \\
\hline Model A & 8,030 & $-27,320$ \\
\hline Model B & 12,894 & $-27,435$ \\
\hline Model C & 12,941 & $-27,538$ \\
\hline Model D & 13,112 & $-27,620$ \\
\hline
\end{tabular}

indicates that the hierarchical structure of apartments units, and spatial as well as serial correlations, should be considered explicitly when modelling the rent-to-price ratio. Therefore, we choose Model D as our final model, the specifications of which are given in the Model formula subsection.

\section{Model calibration and results}

\subsection{Algorithm for model calibration}

Approaches to estimate parameters in a model can vary, but they can be classified into two broad categories: the frequentist approach and the Bayesian approach. The frequentist approach, which might include maximum likelihood estimation, has been criticized recently for its ambiguous concept of confidence intervals and insufficient representation of uncertainty about the parameters, among other flaws. The Bayesian approach emerged as an alternative to the frequentist approach, and is now being considered a standard tool in quantitative studies (Stegmueller, 2013). The main reason for the Bayesian approach being adopted as a common method for estimating parameters lies in the fact that Markov Chain Monte Carlo (MCMC), a simulation based algorithm for implementing Bayesian estimation, has become rapidly accessible to wide range of scholars.

MCMC provides a flexible tool for analyzing quantitative data within the framework of the Bayesian approach, but it also comes with some faults, among them long computing times and slow convergence. We employ the Integrated Nested Laplace Approximations (INLA) algorithm proposed by Rue, Martino, and Chopin (2009), a deterministic algorithm for Bayesian inference, rather than simulation based, such as MCMC. INLA is a recent alternative to MCMC for fitting Bayesian models, and yields more accurate results compared to MCMC and shorter computing times (Blangiardo \& Cameletti, 2015, p. 104). Therefore, INLA can be an efficient tool for modeling hierarchical models with complicatedly structured large data, such as one with temporal and spatial covariance structures (Beguin, Martino, Rue, \& Cumming, 2012).

\subsection{Results}

To estimate relevant parameters and hyper-parameters, we cast formula (1)-(6) into the INLA algorithm, and the results are shown in Table 4.

The goodness of the fit of models including candidate models is shown in Figure 6. Fitted values from our final model (Model D) do not show a noticeable difference from observed ratio values, and thus, we judge that we have no serious problem in leading a discussion based on the results of Table 4. As for the significance of coefficients, the 95th percentile ranges of all the coefficients do not overlap zeros except the 3-year bond interest rate, $\beta_{3-\text { year bond }}$, which indicates that most explanatory variables have their roles in explaining the rent-to-price ratio.

We need to examine the coefficient on the 3-year bond interest rate in detail, since the 95th percentile range includes zero. The distribution of coefficient values for it is illustrated in Figure 7. Its mean value and median value are 0.0414 and 0.0417 , respectively, and most of the values are positive, implying that although there is some uncertainty, the 3-year bond interest rate plays a considerable role in increasing the rent-to-price ratio.

\section{Discussion and conclusion}

We examine determinants of the rent-to-price ratio based on analysis of fixed effects, and explore variations in the ratio through analysis of random effects.

Table 4. Model fit results

\begin{tabular}{|c|c|c|c|c|}
\hline Parameter & Mean & 2.5th percentile & 50th percentile & 97.5th percentile \\
\hline$\beta_{0}$ & 0.5862 & 0.4430 & 0.5857 & 0.7323 \\
\hline$\beta_{\text {age }}$ & 0.0135 & 0.0112 & 0.0135 & 0.0158 \\
\hline$\beta_{\text {age }}{ }^{2}$ & -0.0005 & -0.0006 & -0.0005 & -0.0005 \\
\hline$\beta_{\text {area }}$ & 0.0143 & 0.0073 & 0.0143 & 0.0213 \\
\hline$\beta_{3-\text { year bond }}$ & 0.0414 & -0.0308 & 0.0417 & 0.1118 \\
\hline$\beta_{\text {floor }}$ & -0.0004 & -0.0007 & -0.0004 & -0.0001 \\
\hline$\sigma^{2}$ & 0.0045 & 0.0044 & 0.0045 & 0.0046 \\
\hline$\sigma_{v_{0}}^{2}$ & 0.0030 & 0.0026 & 0.0030 & 0.0036 \\
\hline$\sigma_{\gamma}^{2}$ & $7.5 e-05$ & $3.4 \mathrm{e}-05$ & $8.2 \mathrm{e}-05$ & $21.6 \mathrm{e}-05$ \\
\hline $\mathrm{r}$ & $3,711 \mathrm{~m}$ & $2,652 \mathrm{~m}$ & $3,437 \mathrm{~m}$ & $4,941 \mathrm{~m}$ \\
\hline
\end{tabular}



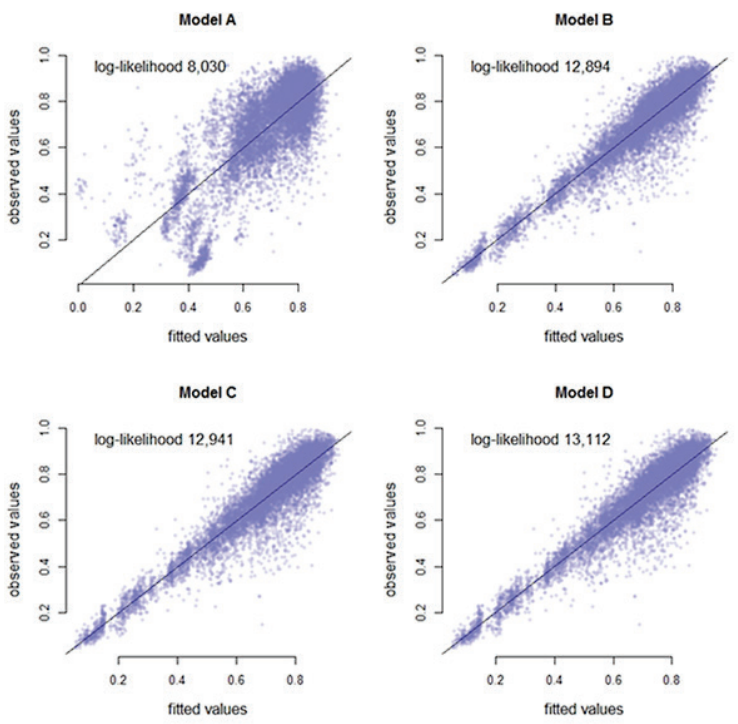

Figure 6. Goodness of the fit of models

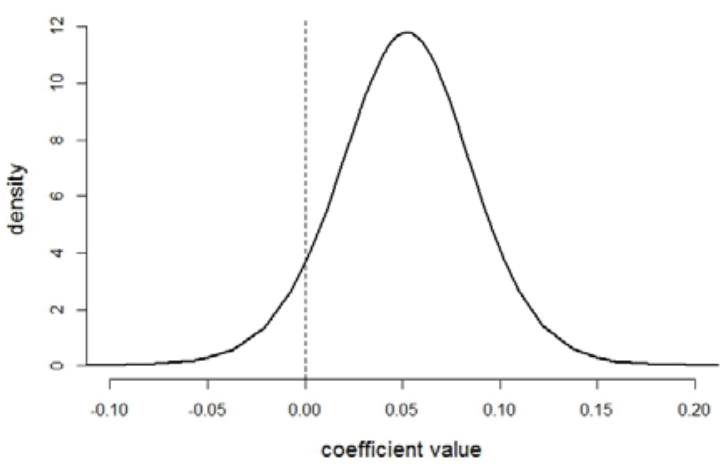

Figure 7. Distribution of coefficient values for the 3-year bond interest rate

\subsection{Analysis of fixed effects}

The coefficients on age and its squared term are estimated to be positive and negative, respectively. The age distribution in the data ranges from 0 years to 45 years, and the ratio movement along this range in accordance with the estimated coefficients is illustrated in Figure 8. The rent-toprice ratio shows little change between 0 and 15 years, and after around 15 years, the ratio begins to drop drastically, indicating that the demand for leases decreases rapidly when apartment complexes are over 15 years old. When an apartment complex is more than 15 years old, it begins to check and replace worn-out water pipelines, gas installations, and elevators. The deteriorated facilities and inferior building conditions mean that demand for renting apartment units within the complex will be reduced, lowering the rent-to-price ratio, which is shown clearly in the Figure 8 . The 95 th percentile range becomes wider as property age goes from 0 to 40 years old, implying that property age has an effect of lowering the ratio, but the extent of decrease is relatively uncertain for old apartment complexes.

We find a positive coefficient on unit area, which indicates that an increase in unit area is associated with an

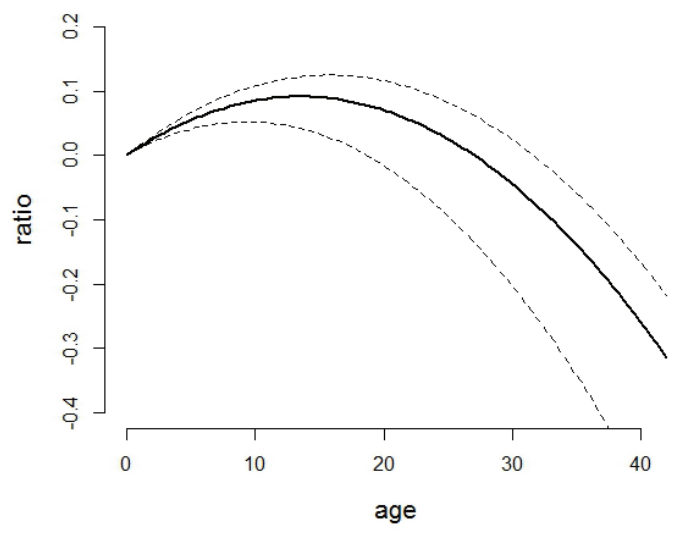

Figure 8. Fixed effect of property age

Solid line denotes the median value, and the upper and lower dotted lines indicate 2.5 th percentile and 97.5 th percentile values, respectively.

increase in the rent-to-price ratio. There exist specific unit areas that are preferred by particular tenants, those specific areas being $59 \mathrm{~m}^{2}$ and $84 \mathrm{~m}^{2}$. The $59 \mathrm{~m}^{2}$-unit is most favored by newly married couples and single-person households. The $84 \mathrm{~m}^{2}$-unit is especially preferred by households with more than two people. Since the unit area starts from $25 \mathrm{~m}^{2}$ (in Table 2), and there are few units in the range after $84 \mathrm{~m}^{2}$, an increase in unit area means that the unit area becomes closer to one of the two favorite unit areas, and naturally leads to an increase in rent, ultimately raising the ratio.

If the 3-year bond interest rate becomes lower, it would be expected to boom up housing sale prices, thus shifting the rent-to-price ratio to lower levels, which is consistent with the positive coefficient on $\beta_{3-\text { year bond }}$. Sommer, Sullivan, and Verbrugge (2013) find that the combination of low interest rates and reduced down payment requirements leads to a large increase in the equilibrium house price, but has little effect on the equilibrium rent. Therefore, as the interest rate goes lower, the rent-to-price ratio drops, which is consistent with the result of this study. There is one point which deserves our attention. The 95th percentile coefficient range for the interest rate includes zero, meaning that there is some uncertainty in the interpretation given above.

The coefficient on the floor level is estimated to be below zero. The negative coefficient indicates that rents do not increase enough to keep up with an increase in prices as the floor on which a unit is located rises. House purchasers in S. Korea usually have a strong preference for units located on middle floors, which are often called "premium floors". For example, the fifth to fourteenth floors are usually referred to as premium floors in the case of a fifteen story apartment building. Units on the premium floors generally command a $10 \%$ to $20 \%$ higher market value compared to ones on the non-premium floors. In contrast, tenants are not willing to pay rents as much as the increase in price accrued from the premium floors, and thus lowers the rent-to-price ratio.

In summary, explanatory variables (age, unit area, 3-year bond interest rate, and floor) employed in the model are found to have significant effects on the ratio at the individual house unit level, and the signs of all the coefficients are consistent with general expectations in the housing market. 


\subsection{Analysis of random effects}

Three random effects in the final model are worth noting: the unit-level variance $\left(\sigma^{2}\right)$, the complex-level variance $\left(\sigma_{v_{0}}^{2}\right)$, and the variance related to the serial correlation $\left(\sigma_{\gamma}^{2}\right)$. Decomposing the total variance can provide additional insights into the interpretation given above, and the proportion of each variance is shown in Table 5. As seen in the table, the variation from individual apartment units $\sigma^{2}$ explains $59 \%$ of the overall variation in ratios across Seoul, and the contribution of apartment complex effects $\sigma_{v_{0}}^{2}$ is around $40 \%$, which cannot be ignored in analyzing the total variance. The effects of apartment complex are suggested graphically in Figure 9, and the figure shows coefficient values for each complex from number 1 to number 919. The rent-to-price ratio is lowered by as much as 0.3 or raised by as much as 0.1 , depending on the complex in which a unit is located.

The month effect $\sigma_{\gamma}^{2}$ represents about $1 \%$ of the overall variation, which can be interpreted as trivial when decomposing the total variance. However, when we see the serial effect shown in Figure 10, we find that the coefficient of each month is similar to the pattern of serial correlation of the raw rent-to-price ratio shown in Figure 4, although the coefficient values oscillate between much smaller intervals, roughly from -0.03 to 0.03 .

Location is the most important aspect in property valuation. It is the property appraisers' creed: location, location, location. It says that even identical houses can be sold or rented for vastly different considerations depending on location. It is the first law in property valuation, though frequently ignored when modelling and predicting housing prices (Kiel \& Zabel, 2008). An important concept related to the property location is the range. The range $r$ is the distance at which the rent-to-price ratios of units in two complexes are spatially uncorrelated. The mean range value is estimated to be $3,711 \mathrm{~m}$, and the 2.5 th and 97.5 th percentile values are 2,652 $\mathrm{m}$ and 4,941 $\mathrm{m}$ respectively (Table 4). Therefore, it implies that when two complexes are geographically separated by a distance between $2,652 \mathrm{~m}$ and $4,941 \mathrm{~m}$, then the prices, the rents, and their ratios in one complex have little influence on those in the other complex, at least in the case of apartments in Seoul. To put it another way, price and rents are inter-correlated when complexes are located within $2,652 \mathrm{~m}$ and $4,941 \mathrm{~m}$ of one another.

\subsection{Concluding remarks}

We investigated the rent-to-price ratio of apartment units in Seoul during the period of the year 2016, with "rent"

Table 5. Variance decomposition

\begin{tabular}{|l|c|c|}
\hline Parameter & Mean estimate & Proportion \\
\hline$\sigma^{2}$ & 0.0045 & $59 \%$ \\
\hline$\sigma_{v_{0}}^{2}$ & 0.0030 & $40 \%$ \\
\hline$\sigma_{\gamma}^{2}$ & 0.000075 & $1 \%$ \\
\hline & & $100 \%$ \\
\hline
\end{tabular}

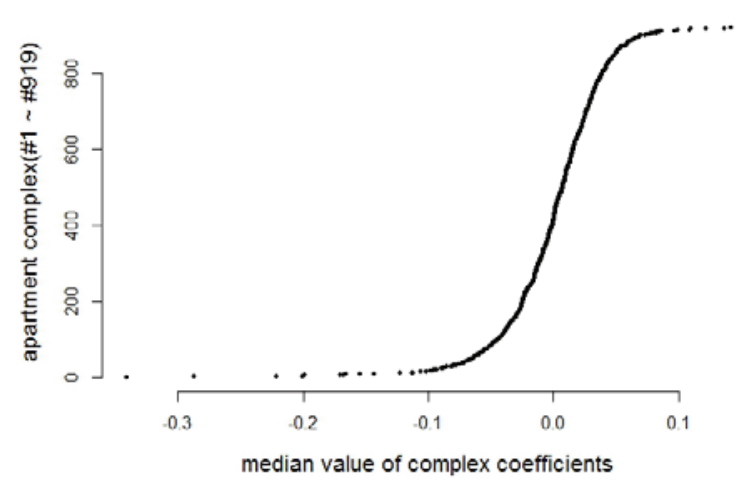

Figure 9. Distribution of complex coefficients

The complexes are sorted by their median coefficients. The range of the complex coefficients goes roughly from -0.3 to 0.1 , which leads to a great difference in the ultimate ratio of an apartment unit.

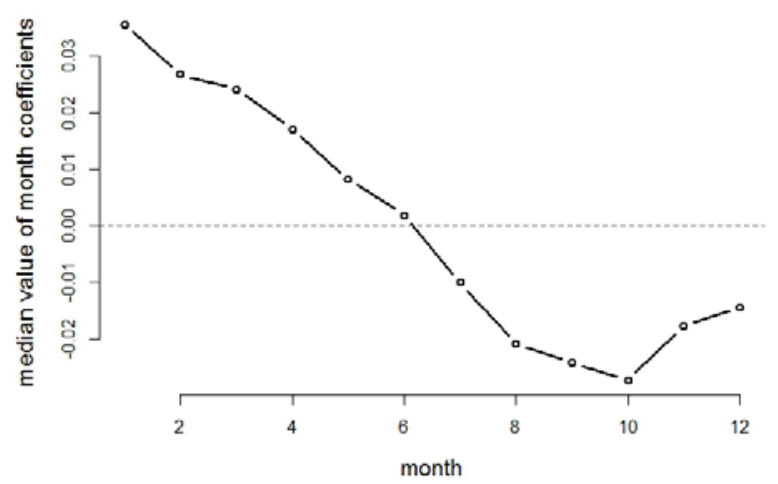

Figure 10. Month coefficients estimated from the model

in this study referring to the Jeonsei deposit. We matched the unit sold and the one leased based on four criteria: apartment complex, unit area, floor level, and month the contracts were made, in order to reduce the fallacy of "comparing apples and oranges" as much as possible. Four explanatory variables and three data features were taken into account when building a model. The former comprises unit area, floor, property age, and the interest rate, and the latter comprises hierarchical structure of units nested in the complex, seasonal variation, and effect of geographical location. We employed the INLA algorithm in order to estimate parameters in the model, since the algorithm is efficient in finding relevant parameters in a hierarchical model and large data with complex structure.

We found and interpreted determinants of the rent-toprice ratio at the property level. The first one is that the ratio is found to drop noticeably after it reaches 15 years old, since the lease demand for apartments older than 15 years decreases due to worn-out facilities and inferior building conditions. Secondly, unit area plays a role in raising the ratio, since the increase in unit area means that the unit becomes closer to one of two favorite unit types; that is, $59 \mathrm{~m}^{2}$-unit and $84 \mathrm{~m}^{2}$ unit. Third, the low interest rate is found to be associated with the rise of housing sale prices, and thus lowering the ratio. Finally, the floor on which a unit is located is found to 
be inversely related to the ratio, and it can be interpreted that rents do not increase enough to keep pace with an increase in prices as the floor rises to so-called "premium floors".

Stepping from the practice of using a single error variance at an observational level, or the apartment unit level, we utilized additional random effects: the complex-level variance $\left(\sigma_{v_{0}}^{2}\right)$ and temporal variance $\left(\sigma_{\gamma}^{2}\right)$. The complexlevel variance represents $40 \%$ of the total variance, which is large enough to deserve special handling when specifying a model. The temporal variance, though its absolute magnitude is trivial, was found to play a role in adjusting the ratio in accordance with its seasonal pattern.

This study tried to explain the aspect of the rent-to-price ratio in Seoul, which has not been touched upon clearly in past studies. First, we analyzed the relationship between sale prices and rents of housing at the apartment unit level from the spatial perspective. This approach has been rarely taken in past studies. Based on the ratio of individual apartment units, we could suggest that the ratio varies remarkably depending on the complex to which a unit belongs and its particular geographical location within the studied area of Seoul. Figure 11 shows the fitted ratio distributions from our final model as of October, 2016, with 2.5th, 50th, and 97.5th percentiles of the fitted values, respectively. October of 2016 was chosen as an illustrative time point since house transactions occurred most frequently at that time $(1,474$ cases reported as shown in Table 2). The low ratio area appears consistently at the southeastern region of Seoul for all the three percentile maps, which is due to considerable apartment complexes being at a stage with imminence of demolition and reconstruction. As an apartment complex ages and comes nearer to that stage, the demand for leases drops sharply, whereas the sale prices rise rapidly due to the reconstruction premium such as expected price appreciation for a newly proposed apartment. This micro-scale spatial analysis makes the study different from past studies, and frees it from the biases introduced by aggregation of data.

Second, we revealed the features in the ratio of S. Korean housing market, such as its determinants and variations. We presented important determinants or factors affecting the ratio based on the property level analysis. Determinants reviewed in this study (property age, unit area, interest rate, and floor) were all proven to have an impact on forming the ratio of a particular apartment unit. We also proved the necessity of considering both seasonal and spatial variations when analyzing the rent-to-price ratio. Therefore, the determinants suggested by this study and the types of variations investigated by our model deserve their due attention when utilizing the ratio. For example, the determinants found in the study should be taken into account when local governments diagnose housing submarkets within the same city. Most previous studies could not provide these kinds of micro-scale determinants of the ratio. Moreover, the cross-sectional determinants at the property level could be useful for local officials in better predicting movement of the ratio aggregated at the national level over long periods. The findings from this study could also provide strategic insights for property companies. For instance, a property company could find the reason as
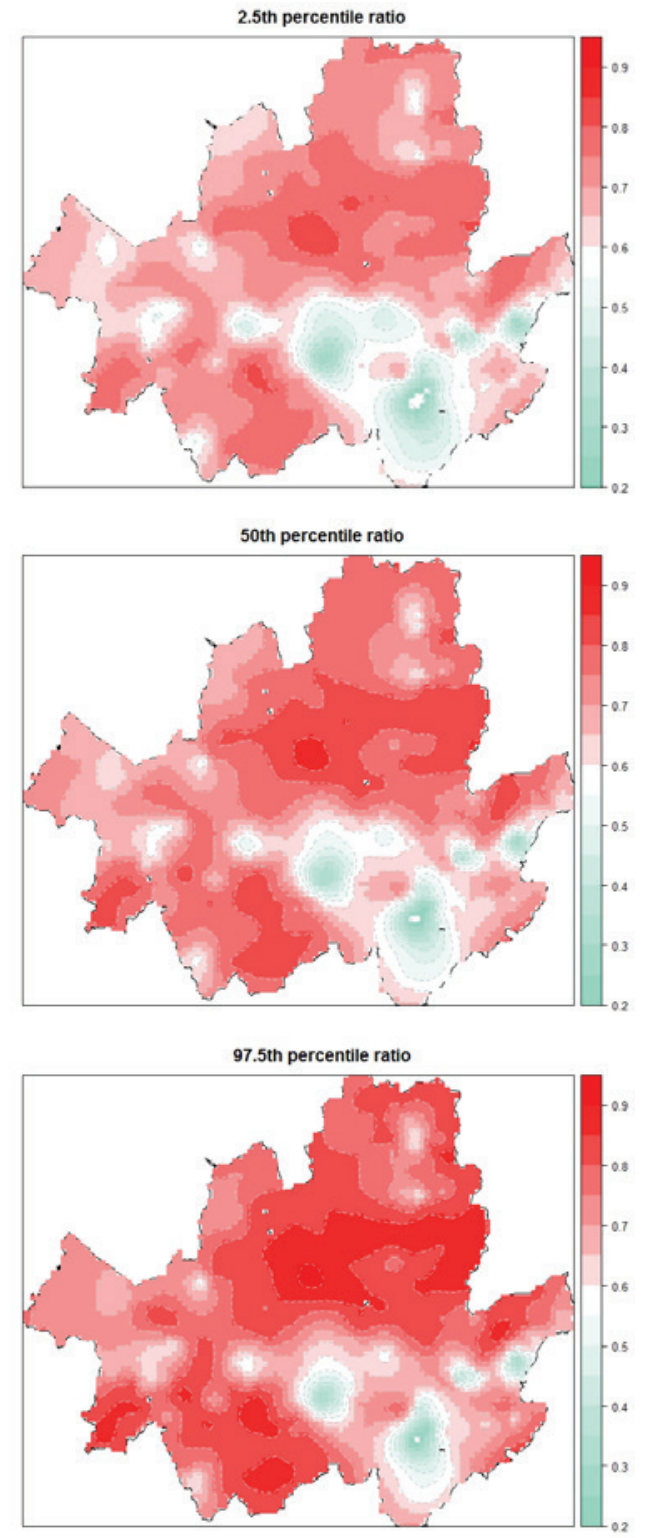

Figure 11. Fitted ratio distributions as of October, 2016

to why a particular lease apartment complex has a relatively high vacancy rate by reviewing the ratio determinants or variations explored in this study. The company could even choose to monitor a particular submarket area where the rent-to-price ratio at the micro-scale is relatively high, since the submarket area can be interpreted as having potential for high lease demand in the near future, and is therefore a good candidate area for purchasing a new lease apartment.

Finally, this study demonstrated an empirical advantage of multilevel modeling approach, and the practical applicability of the INLA algorithm. We showed the flexibility of a multilevel model in analyzing multi-error structures and contextual data that are characteristic of time series cross-sectional data. As shown in Figure 9, we provided apartment complex coefficients (proxy values for context effects), which not only lower the ratio by as much as 0.3 , but also raise it by as much as 0.1 , ultimately leading to the maximum ratio difference of 0.4 for identical 
apartment units except the complex to which they belong. In addition, based on the INLA algorithm, we could successfully estimate parameter values and their uncertainty for relatively large space-time data. We hope this algorithm will reach a wider audience in real estate literature.

\section{Conflict of interest}

On behalf of all authors, the corresponding author states that there is no conflict of interest.

\section{References}

André, C., Gil-Alana, L. A., \& Gupta, R. (2014). Testing for persistence in housing price-to-income and price-to-rent ratios in 16 OECD countries. Applied Economics, 46(18), 2127-2138. https://doi.org/10.1080/00036846.2014.896988

Ayuso, J., \& Restoy, F. (2006). House prices and rents: an equilibrium asset pricing approach. Journal of Empirical Finance, 13(3), 371-388. https://doi.org/10.1016/j.jempfin.2005.10.004

Baltagi, B. H., \& Li, J. (2014). Further evidence on the spatiotemporal model of house prices in the United States. Journal of Applied Econometrics, 29(3), 515-522. https://doi.org/10.1002/jae.2372

Banerjee, S., Carlin, B. P., \& Gelfand, A. E. (2014). Hierarchical modeling and analysis for spatial data. CRC Press.

Beguin, J., Martino, S., Rue, H., \& Cumming, S. G. (2012). Hierarchical analysis of spatially autocorrelated ecological data using integrated nested Laplace approximation. Methods in Ecology and Evolution, 3(5), 921-929. https://doi.org/10.1111/j.2041-210X.2012.00211.x

Blangiardo, M., \& Cameletti, M. (2015). Spatial and spatiotemporal Bayesian models with R-INLA. John Wiley \& Sons. https://doi.org/10.1002/9781118950203

Campbell, S. D., Davis, M. A., Gallin, J., \& Martin, R. F. (2009). What moves housing markets: a variance decomposition of the rent-price ratio. Journal of Urban Economics, 66(2), 90102. https://doi.org/10.1016/j.jue.2009.06.002

Chen, A. (1996). China's urban housing reform: price-rent ratio and market equilibrium. Urban Studies, 33(7), 1077-1092. https://doi.org/10.1080/00420989650011519

Commons, W. (2012). Wikimedia commons. Retrieved from https://en.wikivoyage.org/wiki/Talk:Seoul

Davis, M. A., Lehnert, A., \& Martin, R. F. (2008). The Rent-price ratio for the aggregate stock of owner-occupied housing. Review of Income and Wealth, 54(2), 279-284. https://doi.org/10.1111/j.1475-4991.2008.00274.x

Gallin, J. (2008). The long-run relationship between house prices and rents. Real Estate Economics, 36(4), 635-658. https://doi.org/10.1111/j.1540-6229.2008.00225.x

Goldstein, H., Pan, H., \& Bynner, J. (2004). A flexible procedure for analyzing longitudinal event histories using a multilevel model. Understanding Statistics, 3(2), 85-99. https://doi.org/10.1207/s15328031us0302_2

Hattapoglu, M., \& Hoxha, I. (2014). The dependency of rentto-price ratio on appreciation expectations: an empirical approach. Journal of Real Estate Finance and Economics, 49(2), 185-204. https://doi.org/10.1007/s11146-013-9423-2

Hatzvi, E., \& Otto, G. (2008). Prices, rents and rational speculative bubbles in the Sydney housing market. Economic Record, 84(267), 405-420. https://doi.org/10.1111/j.1475-4932.2008.00484.x

Holly, S., Pesaran, M. H., \& Yamagata, T. (2010). A spatio-temporal model of house prices in the USA. Journal of Econometrics, 158(1), 160-173. https://doi.org/10.1016/j.jeconom.2010.03.040
Ian, H. (2010). An introduction to geographical information systems. Pearson Education India.

Kang, S. W., Shin, Y. S., Lee, T. J., Kang, E. J., Kim, T. W., Choi, H. S., \& Lim, Y. S. (2006). A study on social polarization in Korea. Korea Institute for Health and Social Affairs.

KB Kookmin Bank. (2017). Ratio of Jeonseito purchase price for apartment. Monthly Market Report (Sep. of 2017).

Kiel, K. A., \& Zabel, J. E. (2008). Location, location, location: the 3L approach to house price determination. Journal of Housing Economics, 17(2), 175-190. https://doi.org/10.1016/j.jhe.2007.12.002

Kim, J., \& Lim, G. (2014). Understanding the Irish price-rent ratio: an unobserved component approach. Applied Economics Letters, 21(12), 836-841. https://doi.org/10.1080/13504851.2014.892191

Kim, J. H., Choi, M. J., \& Ko, J. (2009). Mismatch between homeownership and residence in Korea. Housing Finance International, 24(1), 27-33.

Kishor, N. K., \& Morley, J. (2015). What factors drive the pricerent ratio for the housing market? A modified present-value analysis. Journal of Economic Dynamics and Control, 58, 235249. https://doi.org/10.1016/j.jedc.2015.06.006

Korean Statistical Information Service (KOSIS). (2016). S. Korea. Retrieved from www.kosis.kr

Laurini, M. P. (2017). A continuous spatio-temporal model for house prices in the USA. The Annals of Regional Science, 58(1), 235-269. https://doi.org/10.1007/s00168-016-0801-6

Lee, C. M., Chung, E. C., \& Choi, S. E. (2009). An empirical analysis on Chonsei to monthly rent conversion rate in the apartment rental market. Housing Studies Review by the Korean Association for Housing Policy Studies, 17(2), 213-229.

Lindgren, F., Rue, H., \& Lindström, J. (2011). An explicit link between Gaussian fields and Gaussian Markov random fields: the stochastic partial differential equation approach. Journal of the Royal Statistical Society: Series B (Statistical Methodology), 73(4), 423-498. https://doi.org/10.1111/j.1467-9868.2011.00777.x

Park, B. (2002). A theoretical review on Chonsei and monthly rent system. Journal of the Korea Real Estate Analysts Association, 8(2), 57-69.

Pesaran, M. H. (2006). Estimation and inference in large heterogeneous panels with a multifactor error structure. Econometrica, 74(4), 967-1012. https://doi.org/10.1111/j.1468-0262.2006.00692.x

Ronald, R., \& Jin, M. (2015). Rental market restructuring in South Korea: The decline of the Chonsei Sector and its implications. Housing Studies, 30(3), 413-432. https://doi.org/10.1080/02673037.2014.970142

Rue, H., Martino, S., \& Chopin, N. (2009). Approximate Bayesian inference for latent Gaussian models by using integrated nested Laplace approximations. Journal of the Royal Statistical Society: Series B (Statistical Methodology), 71(2), 319-392. https://doi.org/10.1111/j.1467-9868.2008.00700.x

Seoul. (2016). Seoul Statistics. Department of housing policy.

Shiller, R. J. (2015). Irrational exuberance. Princeton University Press, Princeton, NJ. https://doi.org/10.1515/9781400865536

Shor, B., Bafumi, J., Keele, L., \& Park, D. (2007). A Bayesian multilevel modeling approach to time-series cross-sectional data. Political Analysis, 15(2), 165-181. https://doi.org/10.1093/pan/mpm006

Sommer, K., Sullivan, P., \& Verbrugge, R. (2013). The equilibrium effect of fundamentals on house prices and rents. Journal of Monetary Economics, 60(7), 854-870. https://doi.org/10.1016/j.jmoneco.2013.04.017

Stegmueller, D. (2013). How many countries for multilevel modeling? A comparison of frequentist and Bayesian approaches. American Journal of Political Science, 57(3), 748761. https://doi.org/10.1111/ajps.12001 